\title{
Pancreatic Anastomotic Leak, CTCAE
}

National Cancer Institute

\section{Source}

National Cancer Institute. Pancreatic Anastomotic Leak, CT CAE. NCI Thesaurus. Code C143729.

A finding of leakage due to breakdown of a pancreatic anastomosis (surgical connection of two separate anatomic structures). 